\title{
A AGRICULTURA FAMILIAR COMO ALTERNATIVA PARA O DESENVOLVIMENTO TERRITORIAL NA AMAZÔNIA FAMILY AGRICULTURE AS AN ALTERNATIVE TO TERRITORIAL DEVELOPMENT IN THE AMAZON
}

\author{
Igor Luiz Fernandes Corrêa ${ }^{1}$ \\ Rosana Quaresma Maneschy²
}

\section{RESUMO}

O presente artigo tem como proposta contribuir para a discussão sobre a agricultura familiar e o desenvolvimento territorial na Amazônia, analisando os limites e potencialidades deste segmento para a promoção do desenvolvimento pela abordagem territorial. No decorrer do texto apresentam-se os principais conceitos teóricos de desenvolvimento territorial, as características gerais da agricultura familiar(destacando as unidades familiares de produção da região amazônica), suas potencialidades e limitações, relaçõessociais e a perspectiva governamental de lidar com este segmento através de suas ações. Para realização deste artigo foi realizada pesquisa exploratória descritiva, onde foram levantadas informações bibliográficas e documentais sobre o objeto de estudo, além das interações resultantes. Diante das informações percebeuse que a agricultura familiar possui potencial para ser uma alternativa para promoção do desenvolvimento territorial na Amazônia. Contudo, esta necessita ter suas organizações sociais fortalecidas a fim de criar alternativas para ultrapassar as barreiras limítrofes para um desenvolvimento diferenciado em relação ao paradigma estabelecido que prioriza o aspecto econômico.

Palavras-chave: Agricultura familiar. Desenvolvimento Territorial. Amazônia.
ABSTRACT
This article aims to contribute to the discussion on family agriculture and territorial development in the Amazon, analyzing the limits and potentialities of this segment for the promotion of development by the territorial approach. The main theoretical concepts of territorial development, the general cha- racteristics of family agriculture (highlighting the family production units of the Amazon region),
1 Especialista em Gestão Ambiental e mestrando no Programa de Pós-Graduação em Gestão de Recursos Naturais e Desenvolvimento Local na Amazônia (PPGEDAM) - NUMA/UFPA. E-mail: ilfcorrea@hotmail.com
2 Doutora em Ciências Agrárias pela UFRA e professora do NUMA/UFPA. E-mail: romaneschy@ufpa.br 
their potentialities and limitations, social relations and the governmental perspective of dealing with this segment through of their actions. For the accomplishment of this article, a descriptive exploratory research was carried out, where bibliographical and documentary information on the object of study was gathered, besides the resulting interactions. In view of the information, it was noticed that family farming has the potential to be an alternative for the promotion of territorial development in the Amazon. However, it needs to have its social organizations strengthened in order to create alternatives to overcome the boundary barriers for a differentiated development in relation to the established paradigm, which prioritizes the economic aspect.

Keywords: Family agriculture. Territorial Development. Amazon.

\section{INTRODUÇÃO}

O processo ocupacional vivenciado na região Amazônica de modo inicial foi um modelo predominantemente com características exógenas, em que o processo foi sustentado a partir de elevadas taxas de investimentos do setor público voltados para a infraestrutura da região. E que a curto, médio e longo prazo gerou enormes problemas e conflitos territoriais (BECKER, 2001). Esse processo alterou a estrutura fundiária e promoveu crescente marginalização dos agricultores familiares, reproduzindo um padrão de desenvolvimento rural bastante excludente e desigual.

O presente texto tem como proposta contribuir com a discussão sobre o desenvolvimento territorial e a agricultura familiar na Amazônia, mediante a análise dos limites e potencialidades deste segmento produtivo. Logo visa promover uma discussão com ênfase descritiva sobre novas perspectivas que ampliem o campo de atuação das estratégias de desenvolvimento. Este estudo parte do seguinte questionamento: a agricultura familiar possui potencial para ser uma alternativa para a promoção do desenvolvimento territorial na Amazônia? A partir desta problematização adotouse como procedimento metodológico o levantamento bibliográfico direcionado ao tema proposto, destacando as características organizacionais e relacionais da agricultura familiar e fazendo um paralelo com conceitos chave relacionados ao desenvolvimento territorial encontrados em artigos que abordam o tema.

O texto organiza-se em quatro seções, além desta introdução, onde na seção seguinte (2) é exposta a noção de Desenvolvimento Territorial e os conceitos considerados chaves para que ele ocorra. Em seguida, na seção 3, caracteriza-se a agricultura familiar de modo geral e na Amazônia. Na seção 4, dedica-se a analisar este segmento como alternativa para promoção do desenvolvimento territorial; e na última seção (5) são feitas considerações finais em relação a análise realizada.

\section{DESENVOLVIMENTO TERRITORIAL}

Historicamente, o Estado utilizou para seu planejamento e ações governamentais o conceito de região, inclusive para a implantação de políticas públicas. Esta perspectiva de desenvolvimento estava intimamente relacionada com o crescimento econômico, onde se fomentou a nível federal a implantação de grandes projetos estruturantes na região amazônica, com a justificativa de integrar 
a região ao restante do país. Com isso, o governo buscou investir em produções direcionadas ao mercado exterior e diminuição as desigualdades espaciais, como estradas e portos.

Outro tipo de política utilizada, a nível estadual, foi a de atração por novos investimentos através de isenções fiscais, entre outros benefícios ofertados por nossos governantes. Estes investimentos foram feitos principalmente por parte de indústrias oriundas de capital externo (multinacionais) e muitas vezes sem uma consulta à população, que de fato são os que sofrem os impactos (mesmo que estes impactos não sejam restritamente locais).

Contudo, o conceito de território começa a ter maior relevância justamente a partir da perda de espaço da abordagem regional como instrumento para o planejamento das ações governamentais.

Segundo Vasconcellos Sobrinho (2013), o desenvolvimento regional se mostrou incapaz de apresentar resultados eficientes:

A proeminência do conceito de território emergiu com o desgaste da noção de região e, mais precisamente, de desenvolvimento ou planejamento regional que, apesar das inúmeras proposições e modelos, mostrou uma incapacidade de apresentar resultados de desenvolvimento econômico para o conjunto das sociedades, em particular para as sociedades industriais tardias.

Diante desta ineficiência, o Estado passou a agir, mediante as críticas, de outra forma e a temática territorial ganhou força ao longo da década de 1990 e início dos anos 2000, se tornando referência para as ações do Estado e regulação das políticas públicas. Como salientado por Silva (2008), vários programas surgiram no âmbito do governo federal, elaborados com base em uma perspectiva territorial.

De forma diferenciada dos modelos exógenos de desenvolvimento, a visão territorial busca destacar as peculiaridades endógenas de cada local, se caracterizando por ser uma perspectiva múltipla e complexa, exigindo maior capacidade de gestão para reinterpretar os espaços a partir de um novo prisma. Conforme Haesbaert (2008), esta perspectiva é distante daquela de espaço homogêneo unifuncional, como entendido pela razão dominante anterior, que percebe o espaço apenas como lócus para realização da lógica mercantil. A dimensão territorial busca resultados a partir de formas específicas de interação social, da capacidade de protagonismo dos indivíduos, das empresas e das organizações locais em promover ligações dinâmicas capazes de valorizar seus conhecimentos, suas tradições e seus ecossistemas (ABRAMOVAY, 2003).

O desenvolvimento territorial abrange maior integração e participação dos atores envolvidos em determinado território, incluindo maior organização social, que segundo Abramovay (1999), trata-se de ações cooperativas coordenadas que contribuem para a conquista de educação, saúde, informação e que promove maior confiança mutua, de forma a aumentar a eficiência social de certa localidade.

A afirmação da identidade de determinado território está relacionada a necessidade de identificação e valorização das atividades realizadas, de forma que suas potencialidades sejam desenvolvidas através das características ambientais e culturais constituídas ao longo da história daquele território, que se expressam no modo de vida, apropriação da natureza e das tecnologias utilizadas para acesso aos recursos naturais (ALBAGALI, 2004). 
Ao se definir o contorno territorial, deve-se entender que além de existir aspectos físicos e geográficos, há também movimento e interação. Para Fischer (2002), o território é um campo de forças, ou seja, onde há exercício de poderes em diferentes escalas, que vão do micro local ao global.

A sede local da ação, onde as práticas produtivas e relacionais operam, não necessariamente estão partindo da localidade, mas podendo estar vinculadas a operações de comando distantes, ou seja, em locais com relações globais quase sempre há subordinação, seja social (através de movimentos sociais financiados por organizações externas, veículos de comunicação, políticos, entre outros) ou até mesmo oficializada de forma hierárquica em corporações instaladas (transformações espaciais e sociais ocasionadas por grandes empresas em pequenas organizações produtivas de determinadas localidades). Segundo Santos (2001), o local e o global se superpõem em cada lugar, e, num processo dialético, tanto se associam como se dissociam.

Existem alguns fatores relevantes para melhor compreensão do conceito de desenvolvimento territorial, que em forma de ações agregadas constituem o desenrolar teórico desta abordagem. Contudo, mesmo sendo extremamente importantes e essenciais, nenhum destes fatores isoladamente são capazes de promover o progresso esperado, é necessário que estes fenômenos ocorram de forma conjunta para que se almeje o desenvolvimento territorial.

\subsection{CAPITAL SOCIAL}

O desenvolvimento vincula-se ao reconhecimento da importância das estruturas e relações sociais como possível agente intervencionista da dinâmica local de forma que o capital social propicia relações de cooperação que facilita as ações coletivas geradoras de desenvolvimento territorial (ALBAGALI; BRITO, 2003). Essas estruturas relacionais são colocadas por Abramovay (1999) como recursos, ativo de capital presente, que facilitam algumas ações por parte de indivíduos participantes, tornando possível que se alcancem objetivos que não seriam atingidos caso não existisse o capital social.

Conforme Fisher (2006), capital social refere-se ao conjunto de instituições formais e informais, incluindo hábitos e normas sociais, que afetam os níveis de confiança, interação e aprendizado em um sistema social. Este tipo de capital se mostra mais forte conforme se amplia o círculo de relações sociais em que vivem aqueles que participam de sua construção, ampliando as oportunidades de escolha por parte dos indivíduos (SEN, 1999 apud VASCONCELLOS SOBRINHO, 2013)

\subsection{GOVERNANÇA}

Pode-se entender a governança como a forma de poder compartilhada entre governantes e governados, envolvendo participação, parceria e construção coletiva, ou seja, descentraliza o ato de governar. Genericamente, o conceito de governança refere-se às diferentes maneiras pelas quais os indivíduos e instituições (públicas e privadas) gerenciam seus problemas comuns, acomodando interesses conflitantes ou diferenciados e realizando ações cooperativas. É utilizado não só em relação a instituições e regimes formais de coordenação e autoridade, mas também a sistemas informais (FISHER, 2006). Isto é, o desenvolvimento territorial exige novos tipos de gestão, de forma que as potencialidades endógenas do território ganhem destaque. 


\subsection{INFRAESTRUTURA}

O desenvolvimento territorial além de envolver fatores organizacionais, como o capital social e a governança, também envolve fatores físicos como a infraestrutura. Todo o território necessita de desenvolvimento estrutural (saneamento, energia, comunicação, transporte, entre outros) para auxiliar na produção e acesso aos mercados, auxiliando assim na geração de oportunidade aos mais diversos atores sociais e organizações estabelecidas entre eles.

\subsection{EQUIDADE SOCIAL}

A equidade nos remete a criação de políticas capazes de ampliar estratégias que minimizem obstáculos, sejam eles decorrentes de questões individuais ou sociais, trata-se de reconhecer as desigualdades para promover a justiça social.

Quando se trata de desenvolvimento, se torna necessário fazer referências a conceitos básicos como pobreza e exclusão. É fundamental que em territórios onde a desigualdade e falta de organização social são latentes, o desenvolvimento parta da busca pela diminuição da pobreza e exclusão social. É real e possível que em um mesmo território haja estruturas organizacionais que gere maior inclusão social a determinadas parcelas da população, mas que acabe não alcançando outras. É essencial garantir o acesso de todos a as oportunidades existentes, independentemente das peculiaridades de cada indivíduo e/ou grupo social.

\section{AGRICULTURA FAMILIAR}

A agricultura familiar se caracteriza por estabelecimentos agrícolas, onde o sistema de produção é realizado pela família, de forma que a produção normalmente é voltada para as necessidades internas do grupo familiar, seja alimentar ou por outros tipos de consumo.

Autores como Buainain, Romeiro e Guanziroli (2003) destacam a agricultura familiar como uma atividade extremamente heterógena e que vem se transformando e se adaptando conforme as necessidades da sociedade e sua capacidade de produção. As diferenças encontradas estão relacionadas com a disponibilidade de recursos, acesso ao mercado, capacidade de geração de renda, diversificação da produção e o território que estas famílias estão inseridas.

No entanto, a agricultura familiar historicamente sempre foi um setor marginalizado no Brasil, ficando em segundo plano nas políticas de investimentos do governo. Nas palavras de Costa, Rimkus e Reydon (2008), tal situação foi verificada no governo brasileiro que sempre direcionou suas ações para a produção de bens destinados às exportações por apresentarem uma maior rentabilidade. Isso se mostrou nos incentivos em termos de crédito, pesquisa e demais políticas governamentais restritas a grandes e médios produtores patronais ligados ao "agronegócio".

Portanto, o reconhecimento da agricultura familiar como seguimento produtivo merecedor de um ambiente institucional favorável para o desenvolvimento de suas atividades é um fato relativamente novo na sociedade brasileira. Autores como Veiga (2001), Schneider (2003) e Sachs (2004) chegam a apontá-la como um referencial para um novo modelo de desenvolvimento. 
Com a mudança na abordagem sobre a importância da agricultura familiar na sociedade brasileira, este segmento produtivo vem assumindo proporções nada desprezíveis para a formulação de um projeto de desenvolvimento no país e passou a ser visto como fonte relevante de geração de empregos e ocupações produtivas (MESQUITA; MENDES, 2012).

Segundo Abramovay (2006), a valorização da agricultura familiar no Brasil foi pautada em três planos distintos, a saber:

a) Plano intelectual: onde surgiram diversas pesquisas que permitiram estratificar e capturar a heterogeneidade deste segmento no país, bem como avaliar a sua relevância socioeconômica; b) Políticas públicas: intensificaram-se as ações do governo perante políticas públicas a fim de atingir de forma mais eficiente as famílias caracterizadas como de produção familiar. Pode-se destacar o PRONAF e os projetos de assentamento de reforma agrária. Estas políticas foram responsáveis por buscar gerar novas oportunidades de ocupação e negócios para milhares de famílias.

c) Plano social: a agricultura familiar corresponde a um conjunto de forças organizadas cuja principal bandeira de luta é a afirmação da viabilidade econômica da produção familiar, e, posteriormente, sua consolidação como seguimento importante para a economia social.

Grande parte das ações relacionadas a esses planos foram direcionadas para a Amazônia, onde em termos políticos, a abordagem territorial se mostra presente nas ações dos planejadores e formuladores de políticas governamentais.

\subsection{AGRICULTURA FAMILIAR NA AMAZÔNIA LEGAL}

Na Amazônia a prática da agricultura familiar é de grande diversidade cultural, social e econômica, se mostrando extremamente importante para o contexto local e até mesmo brasileiro (HURTIENNE, 2005). Os diferentes grupos sociais do campo, como posseiros, agricultores familiares, sem-terra e suas organizações de representações, projetaram-se na cena política e forçaram o Estado a estabelecer novas metas, criar novos programas, flexibilizar estruturas e rever orçamentos. Dessa forma, novas solidariedades foram gestadas no seio de lutas que articulavam diferentes atores sociais.

Muitos municípios da Amazônia possuem agricultores familiares em grande proporção e, apesar da disputa crescente com produtores que migram constantemente de outras regiões (principalmente em áreas de expansão da fronteira agrícola), em muitos desses municípios a tradição agrícola e/ ou extrativista é forte, de forma que a agricultura familiar representa a essência da sociedade local, abastecendo o mercado e tendo influência direta quando organizados em sindicatos, colônias de pescadores, cooperativas ou associações (MANESCHY; KLAVDAHL, 2007).

Na região Norte, o Censo Agropecuário de 2006 identificou cerca de 700 mil estabelecimentos familiares ( $86 \%$ do total) ocupando uma área de 25,4 milhões de hectares (22\% da área total dos estabelecimentos). Os estabelecimentos familiares na Amazônia correspondiam naquela data a 16\% (dos números) e 32\% (da área) dos estabelecimentos familiares do Brasil. Ainda revelou indicadores socioeconômicos da agricultura de base familiar na Amazônia que se mostraram maiores que os da agricultura não familiar.

Em 2006, o valor das receitas obtidas pelos estabelecimentos agropecuários com produtos vegetais na região Norte foi de $\mathrm{R} \$ 3$ bilhões, sendo que desse total, a agricultura familiar participou 
com 60\%. Em relação as atividades agrícolas e não agrícolas da região, a agricultura familiar se mostrou extremamente importante para a geração de renda. Considerando toda a Amazônia Legal, os estabelecimentos familiares respondiam por $82 \%$ do total de 3 milhões de pessoas ocupadas na atividade agropecuária regional, sendo que no Brasil, essa proporção em 2006 foi de 74\% (IBGE, 2006).

\section{AGRICULTURA FAMILIAR E O DESENVOLVIMENTO TERRITORIAL}

O enfoque territorial difundido nas últimas três décadas no Brasil trouxe reflexões importantes sobre a necessidade de tratar o desenvolvimento, principalmente o classificado pelo governo como rural, de uma forma multissetorial. Mostrando a agricultura familiar como possível promotora do território, valorizando-o pelos seus atributos culturais, ambientais, sociais, institucionais e econômicos, visando compreender este não apenas como um espaço de produção agropecuária, mas como lugar com necessidades intrínsecas de qualidade de vida e cidadania.

\subsection{A AGRICULTURA FAMILIAR COMO ALTERNATIVA AO DESENVOLVIMENTO TERRITORIAL}

Segundo Sachs (2003), a agricultura familiar deve ser considerada como alavanca para o desenvolvimento. Porém deve-se compreender que a agricultura familiar na Amazônia é caracterizada por possuir grande complexidade, não apenas na sua concepção conceitual, mas também prática, portanto é preciso buscar metodologias efetivas para que haja desenvolvimento territorial a partir do que a agricultura familiar tem para oferecer. Isso engloba diversos fatores importantes, como acesso à terra, informação, capacitação, infraestrutura (energia, rodovias, transporte, entre outros), crédito e aos mercados relacionados ao tipo de atividades desenvolvidas.

Segundo Guanziroli et al. (2009), os países capitalistas que ostentam os melhores indicadores de desenvolvimento são justamente aqueles que adotaram a estratégia de desenvolvimento baseado na atividade familiar e não na patronal como ocorrera no Brasil, onde a gestão e o trabalho foram dissociados, provocando uma imensa desigualdade social.

A perspectiva territorial de desenvolvimento através da agricultura familiar deve ultrapassar as limitações apresentadas pela abordagem regional de desenvolvimento que prevaleceu durante muito tempo na Amazônia. Os atores sociais locais devem ser colocados em papel de destaque, oportunizando-os a produzirem alternativas inovadoras, mas também com base cultural, assim aumentando o destaque da identidade dos territórios existentes na Amazônia Legal.

Veremos a seguir as potencialidades e limitações que este segmento possui para fomentar o desenvolvimento territorial da Amazônia Legal.

\subsubsection{Potencialidades}

A agricultura familiar dinamiza as atividades territoriais, gerando oportunidades de trabalho, sistemas de produção diversificados e processos tecnológicos simples, contribuindo para a redução do êxodo rural. Além de possibilitar atividades econômicas em maior harmonia com a natureza, 
contribuindo para o desenvolvimento a partir da vocação produtiva do próprio território (MACIEL; LIMA JUNIOR, 2011; MEDINA; BARBOSA, 2015).

A produção proveniente de unidades familiares normalmente é diversificada, tendo capacidade de participar de diversas cadeias produtivas, como madeireira, de frutas, grãos, entre outros. Contudo, a atual lógica de desenvolvimento na Amazônia registra pouca internalização de renda e verticalização da produção familiar, gerando concentração de renda e limitação dos resultados. É necessário que haja de fato consideração pelas condições de produção, com base em tecnologias alternativas e apropriadas (OLIVEIRA; MELLO, 2006).

As agroindústrias estabelecidas em pequenas propriedades através de cooperativas de produtores têm mostrado grande potencial mercadológico, evidenciando um aumento das organizações sociais, que podem gerar capital social. Os princípios norteadores da transformação da agricultura familiar se alinham ao associativismo e à participação social (ARAÚJO et al., 2007), buscando alternativas fora do paradigma capitalista. Mas, para tanto, é necessário que o segmento familiar consiga articular movimentos sociais organizados capazes de enfrentar os comportamentos políticos estabelecidos, e se possível ampliar as "redes sociais" e canais de comercialização, para gerar emprego e renda.

Ao corroborar com a ideia de que os agricultores familiares precisam de alternativas para favorecer suas atividades políticas, econômicas e sociais, vê-se a organização social como substrato dos empreendimentos econômicos solidários, ao criar espaços estratégicos no enfrentamento das sequelas da sociedade capitalista e ao garantir-lhes acesso a direitos sociais para seus associados e para o território ao qual estão inseridos (LAVILLE; FRANÇA FILHO, 2004).

Nestes termos, compreende-se que as iniciativas de base econômica solidária, trabalho associado e autogestionário configuram recursos capazes de acumular forças na transição de um modelo socioeconômico pautado pela exploração para um modelo circunscrito à economia dos trabalhadores livremente associados (DAL RI; VIEITEZ, 2008). Segundo Abramovay (2003), as mudanças nas relações com o mercado, novas articulações com atores político-institucionais e alianças com atores de fora do território, por exemplo, podem ser suficientes para reforçar as energias latentes existentes no território, de modo a deslanchar processos de desenvolvimento.

Por essas razões, a economia solidária tem se mostrado importante na agricultura familiar, pois favorece o acesso a bens e serviços que individualmente seria impossível de captar. Suas ações nascem no campo das lutas de resistência, predominantemente, por meio de reivindicações de trabalhadores e trabalhadoras excluídos do mercado de trabalho e com direitos violados (REIS et al., 2015)

As políticas públicas são importantes para diminuição das desigualdades territoriais concebidas horizontalmente, onde criam oportunidades para que agricultores tenham acesso aos recursos que lhes permitem organizar-se a fim de buscar empoderamento. Assim, os agricultores familiares podem ter acesso a maiores direitos sociais que estimulem a solidariedade, confiança e mostre benefícios sociais que possam ser conquistados por sua valorização.

Programas de crédito como o Programa Nacional de Fortalecimento da Agricultura Familiar (PRONAF) e programas de mercados institucionais como o Programa de Aquisição de Alimentos (PAA) e o Programa Nacional de Alimentação Escolar (PNAE), que têm crescido de forma continuada, se mostram bastantes promissores em uma perspectiva de maior autonomia.

Além disso, a proposta de investir no desenvolvimento territorial através da agricultura 
familiar possui outro ponto importante, os serviços ambientais que podem ser prestados pelo manejo sustentável das florestas, e o incentivo ao turismo, que explorado de força eficiente, pode gerar emprego e renda (CAMPANHOLA; SILVA, 2000).

\subsubsection{Limitações}

A pobreza na Amazônia é reconhecidamente um desafio para o alcance do desenvolvimento (MIRANDA et al., 2010), onde predominam a fragmentação e desarticulação econômica e social, com isso defende-se um papel mais ativo do Estado, no sentido de promover a construção de estratégias de desenvolvimento para o território. Se assim não ocorrer, as dinâmicas econômicas e sociais necessárias para viabilizar o desenvolvimento endógeno do território serão dificilmente desencadeadas (ABRAMOVAY, 2003).

As políticas públicas com diferentes abordagens que foram criadas nas últimas décadas trouxeram avanços significativos, aumentando expressivamente a oferta de crédito rural e programas institucionais. Contudo, exige-se maior organização social por parte do segmento familiar, para que se criem alternativas perante os paradigmas políticos, pois somente a existência da legislação costuma não assegurar totalmente os direitos. É importante que os sujeitos sociais possuam capacidades de participar de mercados e estabelecer relações que enriqueçam a sua existência. Isso pode contribuir para que os produtores familiares de determinado território se percebam como sujeitos ativos de seu próprio desenvolvimento, fortalecendo-se a partir de movimentos sociais, através de associações, cooperativas e grupos religiosos.

\section{CONCLUSÃO}

As ações produtivas e relacionais de determinado território fortalecem a identidade local, propiciando respostas positivas as influências globais que estes sofrem. De forma que os atores locais percebam seu potencial endógeno de formular estratégias autogestionárias que visam o desenvolvimento. Com isso os efeitos esperados são a heterogeneidade social e econômica dos territórios que gerem movimentos distintos em direção ao desenvolvimento territorial.

Diante das informações analisadas percebeu-se que a agricultura familiar possui potencial para ser uma alternativa para promoção do desenvolvimento territorial na Amazônia Legal, contudo com ressalvas. Há necessidade de fortalecer as relações sociais, de forma que se tornem organizadas e sejam capazes de gerar capital social.

As organizações sociais fortalecidas produzem melhor governança, que a partir de interações sólidas podem direcionar as diretrizes de uma sociedade, para o seu crescimento e desenvolvimento, aumentando a capacidade de buscar soluções e constituírem em parceria novos paradigmas para gestão e ações em prol do bem comum. Este tipo de ação constitui um importante instrumento social capaz de promover o desenvolvimento local de forma democrática e endógena.

Na região o segmento familiar destaca-se por ser maioria em número e área quando comparado aos grandes produtores. Entretanto é necessário que os agricultores tomem consciência da sua importância cultural, social e econômica. Neste contexto, os agricultores familiares podem galgar 
maior destaque na sociedade, participando da tomada de decisões a fim de criar alternativas para ultrapassar as barreiras limítrofes para um desenvolvimento diferenciado em relação ao paradigma exógeno estabelecido na Amazônia.

Alternativas autogestionárias, como a economia solidária, se mostram uma opção interessante, pois mesmo que haja enfraquecimento das políticas direcionadas a agricultura familiar, este segmento da sociedade conseguirá buscar alternativas que tragam melhores condições de vida no local onde se encontram.

\section{REFERÊNCIAS}

ABRAMOVAY, Ricardo. Agricultura Familiar e Reforma Agrária. In: Estudo da Dimensão Territorial do PPA. Brasília: CGEE, 2006.

ABRAMOVAY, Ricardo. O capital social dos territórios: repensando o desenvolvimento rural. IV Congresso da Sociedade Brasileira de Economia Política. Porto Alegre, jun. 1999

ABRAMOVAY, Ricardo. O futuro das regiões rurais. Porto Alegre: Editora UFRGS, 2003.

ALBAGALI, S. Território e territorialidade. In: LAGES, V., BRAGA, C., MORELLI, G. (orgs). Territórios em movimento: cultura e identidade como estratégia de inserção competitiva. Brasília: Sebrae, 2004.

ALBAGAli, S.; BRITO, J. Glossário de Arranjos e Sistemas Produtivos e Inovativos Locais. Rede de Pesquisa em Sistemas Produtivos e Inovativos Locais, 2003.

BECKER, B. K. Revisão das políticas de ocupação da Amazônia: é possível identificar modelos para projetar cenários? Parcerias Estratégicas. n. 12. p. 135-159. 2001.

BUAINAIN, A. M.; ROMEIRO, A. R.; GUANZIROLI, C. Agricultura familiar e o novo mundo rural. Sociologias, n. 5, 2003.

CAMPANHOLA, Clayton; SILVA, José Graziano da. O agroturismo como nova fonte de renda para o pequeno agricultor brasileiro. In: ALMEIDA, Joaquim Anécio. Turismo rural ecologia, lazer e desenvolvimento. São Paulo: EDUSC, 2000.

COSTA, Jair Pereira; RIMKUS, Eah Marie; REYDON, Bastiaan Philip. Agricultura Familiar, Tentativas e Estratégias para Assegurar um Mercado e uma Renda. In: Congresso da Sociedade Brasileira de Economia, Administração e Sociologia Rural, 46., 2008, Londrina. Anais... [...]. Londrina: SOBER, 2008.

DAL RI, N. M.; VIEITEZ, C. G. Educação Democrática e Trabalho Associado no Movimento dos Trabalhadores Rurais Sem Terra e nas Fábricas de Autogestão. São Paulo: Ícone-Fapesp, 2008. 
FISCHER, Tânia. Poderes Locais, gestão e desenvolvimento. Salvador: Casa da Qualidade, 2002.

FISCHER, Tânia; PINHO; José Antônio Gomes de (coord.). Universidade Corporativa Banco do Brasil. Desenvolvimento territorial organizações e gestão. Brasília, 2006.

GUANZIROLI, Carlos. Agricultura familiar e reforma agrária no século XXI. Rio de Janeiro: Garamond, 2009.

HAESBAERT, R. Dilema de conceitos: espaço-território e contenção territorial, 2008.

HURTIENNE, T. P. Agricultura familiar e desenvolvimento rural sustentável na Amazônia, 2005.

IBGE. Censo Agropecuário 2006. Agricultura Familiar. Primeiros resultados. Brasil, Grandes Regiões e Unidades da Federação. Brasília/Rio de Janeiro: MDA/MPOG, 2009.

LAVILLE, J. L.; FRANÇA FILHO, G. C. Economia Solidária, uma abordagem internacional. Porto Alegre: Editora da UFRGS, 2004.

MACIEL, R. C. G.; LIMA JUNIOR, F. B. Inovação e agricultura familiar rural na Amazônia: o caso no estado do Acre. In: Congresso da Sociedade Brasileira de Economia, Administração e Sociologia Rural. 2011, Belo Horizonte. Anais... [...]. Belo Horizonte: SOBER, 2011.

MANESCHY, M. C.; KLAVDAHL, A. Redes de associações de grupos camponeses na Amazônia Oriental (Brasil): fontes de capital social? REDES - Revista Hispana para el Análisis de Redes Sociales, Madrid, v. 12, n. 4, p. 5-19, jun. 2007.

MEDINA, G.; BARBOSA, C. (Org.). Experiências Produtivas de Agricultores Familiares da Amazônia (Segunda edição). Goiânia: Kelps, 2015. 200p.

MIRANDA, H. R.; VASCONCELLOS SOBRINHO, M.; ROCHA, Gilberto de Miranda. Desenvolvimento Territorial Sustentável e Participação Popular na Amazônia: limitações e possibilidades. Movendo Ideias (UNAMA), v. 17, p. 45-54, 2010.

OLIVEIRA, D.; MELLO, M. A. Novas formas de inserção da agricultura familiar ao mercado como estratégia de desenvolvimento rural. In: Congresso da Sociedade Brasileira de Economia, Administração e Sociologia Rural, 44, 2006, Fortaleza. Anais... [...]. Brasília, DF: Sober, 2006. p. 19.

REIS, A.; LUIZ NASCIMENTO, W. N.; OLIVEIRA, A.O.; SANTOS, A.R. Agricultura Familiar e Economia Solidária: a experiência da Associação MUTIRÃO, na região do Baixo Tocantins, Amazônia Paraense. Revista Tecnologia e Sociedade, v. 11, p. 120-142, 2015.

SACHS, Ignacy. Desenvolvimento: includente, sustentável, sustentado. Rio de Janeiro: Garamound, 2004. 
SANTOS, M.; SILVEIRA, M.L. O Brasil: território e sociedade no início do século XXI. Rio de Janeiro: Record, 2001.

SAQUET, M. A.; SPOSITO, E. S. Território e territorialidades: teoria, processos e conflitos. São Paulo: Expressão Popular, 2009, p. 95-120.

SCHNEIDER, Sérgio et al. Agricultura familiar e teoria social: a diversidade das formas familiares de produção na agricultura. SAVANAS: desafios e estratégias para o equilíbrio entre sociedade, agronegócio e recursos naturais, 2008. Planaltina-DF, Embrapa Cerrados, 989-1014.

SCHNEIDER, Sérgio. A pluriatividade da agricultura familiar. P. Alegre: UFRGS, 2003.

SILVA, Sandro Pereira. Políticas públicas e agricultura familiar: uma abordagem territorial do PRONAF no Médio Jequitinhonha. Viçosa: UFV, 2008. Dissertação (Mestrado em Economia). Universidade Federal de Viçosa, 2008.

VASCONCELLOS SOBRINHO, Mário. Notas Introdutórias sobre Desenvolvimento e Desenvolvimento Territorial. In: Desenvolvimento Local e o Direito à Cidade na Floresta Amazônica. 1ed. Belém: NUMA/UFPA, 2013, v. 1, p. 13-37.

VEIGA, José Eli da. O Brasil precisa de uma estratégia de desenvolvimento. Texto para Discussão, nº 1. Brasília: NEAD, 2001. 